\section{MARÉ DE INFORMAÇÃO PARA PROMOVER A CULTURA OCEÂNIICA}

\author{
Germana Barata
}

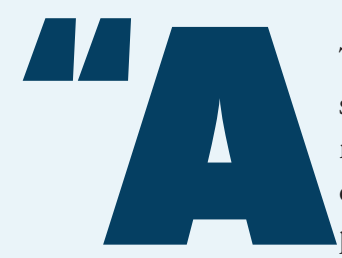

Terra é azul", exclamou o cosmonauta russo Yuri Gagarin em 12 de abril de 1961, durante o primeiro voo espacial humano. Sua constatação mudou, para sempre, nossa percepção sobre a Terra. Com a superfície coberta por mais de $70 \%$ de água salgada, nosso planeta é banhado por um gigantesco oceano que influencia diariamente as vidas de todos seus seres vivos.

A partir deste ano inicia-se a Década do Oceano, um esforço mundial de mudarmos o curso da sociedade, sensibilizá-la para que se aproxime do oceano e perceba que faz parte de um mesmo planeta conectado pela água. O principal desafio para a comunicação é justamente aproximar cada habitante ao oceano que impacta a vida terrena de forma tão intensa.

Segundo dados do IBGE de 2010, pouco mais de 50 milhões de brasileiros e brasileiras (26,6\% da população) moram na zona costeira e, portanto, são impactados diretamente pela maresia, paisagens, fauna e usufruem de atividades econômicas ligadas à cultura oceânica. Enquanto três em cada quatro brasileiros estão distantes do mar e concentrados em centros urbanos nos quais a natureza está pouco presente.

Com a saúde do oceano em risco, não há outro remédio senão mobilizar a humanidade para se familiarizar e se engajar em prol de ações e políticas ambientais que sejam capazes de mitigar e promover adaptações às mudanças que já estão em curso. Acidificação das águas marinhas, elevação do nível do oceano, derretimento das geleiras, encalhe de golfinhos e baleias nas praias, embranquecimento dos corais, superpopulação de algas exóticas (sargaço), diminuiçãoo dos estoques pesqueiros, destruição dos mangues, aumento de tempestades, secas pronunciadas no continente, destruição de calçadões, piers, elevação de ataques de tubarões na costa, níveis elevados de mercúrio nas águas e nos peixes, perda de biodiversidade.

Não faltam notícias ruins, que podem contribuir para uma sensação de impotência na sociedade. Somado a isso, a politização do debate das mudanças climáticas, o negacionismo, a desmoralização das instituiçóes de pesquisa e de cientistas encabeçada pelo governo federal deixam claro que a maré não está para peixes!

PERCEPÇÃO PÚBLICA No país de maior biodiversidade do mundo, qual é a relação da população com a mesma? Nelio Bizzo, da Universidade Federal de São Paulo (Unifesp), e coautores investigaram como alunos da região Norte, de maior biodiversidade do país, e do
Sudeste, região mais populosa e rica, se preocupam com a diversidade biológica. O estudo, publicado na revista Science Advances em agosto de 2020 concluiu que há maior preocupação entre os brasileiros em relação a estudantes de outros países, apesar do menor acesso à informação [1]. No entanto, o contato direto com a natureza, populaçôes indígenas, conhecimento local e a riqueza sociocultural associadas à natureza influenciam positivamente os estudantes do Norte, que se mostram bem mais interessados (50.4\%) no tema do que os jovens do Sudeste (33.1\%).

"As escolas devem abordar o ILK [conhecimento local e indígena] e o conhecimento científico por meio de ações que visem impulsionar a educação científica; caso contrário, atitudes positivas em relação à conservação podem não ser duradouras”, enfatizaram os autores lembrando que em todas as regióes brasileiras há populações indígenas e as colaborações internacionais podem impulsionar a melhora na qualidade do ensino [1]. Nesse contexto, a Década do Oceano é um exemplo concreto que poderá ser, em breve, colocado em prática. Nelio e coautores reconhecem o importante papel que especialistas desempenham na ciência, mas defendem que as soluções práticas relacionadas ao futuro da biodiversidade "devem considerar valores e crenças, e o cidadão comum também deve participar dos processos de tomada de decisão" [1].

A pesquisa brasileira tem características que se assemelham a resultados de enquetes mais específicas sobre a percepção pública sobre a saúde do oceano em que mostra uma alta preocupação, mas baixa informação. No entanto, Jonathon Schuldt, da Cornell University, e colegas revisaram pesquisas sobre a percepção pública sobre o oceano e identificaram três desafios principais para a comunicação sobre a saúde dos oceanos [2]: a) a frequente politização do debate que privilegia a opinião ao invés de evidências científicas; b) o distanciamento psicológico das pessoas em relação ao oceano; e c) a falta de familiaridade e compreensão sobre como funcionam os sistemas oceânicos.

Uma das sugestôes que o artigo traz é de que a comunicação enfatize os impactos que a degradação do oceano tem sobre a saúde humana, como uma forma de aproximação e sensibilização à causa. Eles lembram também que a divulgação de dados científicos de forma amigável e atraente é fundamental para a conscientização social, bem como o uso de metáforas que possam estabelecer conexões com o público. Eles mencionam o Ocean Health Index (Índice de Saúde do Oceano; http://www.oceanhealthindex.org/), uma iniciativa colaborativa internacional que disponibiliza dados e que classifica países costeiros de acordo com o cuidado com a preservação de recursos naturais, biodiversidade, reserva de carbono e tantos outros itens. O Brasil aparece em $65^{\circ}$ lugar numa lista com 221 países e é possível brincar com os diferentes dados e entender onde ainda é preciso melhorar para garantir uma saúde plena, além de comparar com outras nações.

O projeto Maré de Ciência, coordenado por Ronaldo Christofoletti, professor da Unifesp e membro do comitê de assessoramento de gestão da Década do Oceano no Brasil, é um ótimo exemplo sobre as possibilidades que atividades de extensão abrem para fortalecer a cultura 
oceânica. Iniciado com escolas do litoral paulista, em Santos, a partir da tradução do kit pedagógico Cultura Oceânica para Todos [3], da Unesco, o projeto Maré da Ciência organizou o I Fórum Brasileiro dos Jovens Embaixadores do Oceano, em novembro de 2020. O evento reuniu alunos embaixadores do oceano de 24 escolas públicas para compartilhar boas práticas de ensino sobre o tema "Oceano na Educação", com o desafio de propor formas de conectar as pessoas e valorizar a importância do oceano na vida da sociedade. $\mathrm{O}$ evento colaborativo com jovens vai gerar um livro a ser publicado este ano e traz a essência de qualquer comunicação estratégia: diálogo e inclusão social, criatividade e colaboração para a construção de estratégias. Nada trivial, o projeto propõe diálogos necessários e urgentes a partir dos quais será possível investir em uma cultura oceânica mais significativa para todos.

A Década do Oceano deverá também investir em pesquisas de percepção de brasileiros sobre a cultura oceânica, que deve ser repetida ao longo dos anos para que possamos acompanhar as mudanças e ajustar nossas estratégias de comunicação. Exemplo de campanha de grande impacto nessa direção é a \#droptheS (derrube o "s", em tradução livre), um esforço iniciado pelo coletivo One Ocean em 2019, para que os oceanos - Atlântico, Pacífico, Índico, Ártico e Antártico - passem a ser vistos como apenas um único oceano, que banha $71 \%$ da superfície do planeta e conecta a todos.

MAR CALMO NUNCA FEZ BOM MARINHEIRO Dentre os desafios que a divulgação da cultura oceânica tem à frente está a desconexão do público com as águas salgadas. Giovana Savoie, da Universidade de Otago, defende a contação de história como uma forma poderosa de sensibilizar o público [4]. Segundo a pesquisadora, as narrativas sobre mudanças climáticas raramente incluem as vozes daqueles mais afetados diretamente, como as populações das ilhas do Pacífico. "Encorajar a participação em narrativas visuais que abrace perspectivas diversas e envolva o público todo na contação de história da ciência. Vamos usá-la como uma ponte interativa entre oceanos, culturas e demografias, conectando pessoas ao redor do globo e investindo nelas as histórias que afetam nossa humanidade - e, portanto, nossos problemas. Apenas quando compartilharmos a narrativa coletiva da ciência, sua história estará completa”.

Giovana descreve os vídeos da série I am ocean, produzidos pelo Ocean Media Institute, que inovam ao dar voz a outros atores tão relevantes para a cultura oceânica e que têm sido esquecidos. O vídeo sobre o Havaí, por exemplo, traz a voz de uma ancestral da ilha de Pua e sua visão sobre o poderoso ciclo do oceano que impacta e conecta as vidas da população.

É preciso iniciar a Década do Oceano de olho nesses desafios, mas com a perspectiva de que teremos de ser mais ousados, mais inclusivos e empenhados. Uma busca nas redes sociais traz um pouco de alento a esse esforço que está apenas começando - e revela que a maré de divulgação da cultura oceânica está em alta.

Um levantamento inicial nas redes sociais indica que já são mais de 10 podcasts brasileiros dedicados à divulgação do oceano, da ci- ência oceânica, da oceanografia e que levam os ouvintes a navegar águas nunca dantes navegadas. Os podcasts são uma mídia poderosa que pode ser apreciada simultaneamente a percursos no trânsito, tarefas domésticas ou a realização de atividades físicas. Os canais de áudio têm crescido $65 \%$ ao ano, nos últimos quatro anos no Brasil, sendo que $40 \%$ da população afirma já ter ouvido podcast ao menos uma vez. O número de podcasts de ciência cresce exponencialmente desde 2010 no mundo [5](MacKenzie, 2019) e no Brasil desde 2014 [6](Takata, 2019).

De acordo com MacKenzie [5] há poucos podcasts com propósitos educacionais (6\%) e menos de $1 \%$ são voltados para as crianças, justamente um importante público e propósito para a comunicação da cultura oceânica. $\mathrm{O}$ autor identificou que, entre os 952 podcasts de ciência em inglês amostrados, cerca de $6 \%$ cobrem a oceanografia e biologia marinha e dois terços incluem cientistas podcasters, o que demonstra o grande potencial do áudio online como ferramenta de divulgação científica. No entanto, é importante lembrar que a maior parte deles é feita de maneira voluntária e com investimentos próprios dos divulgadores de ciência, o que acaba contribuindo para o grande número de canais que acabam inativos antes de completar um ano de existência. Portanto, linhas de financiamento como o edital aberto em 2020 pelo Instituto Serapilheira para financiar podcasts, independentemente de ligaçôes com instituiçôes acadêmicas, são fundamentais para valorizar os esforços feitos em prol da comunicação da ciência brasileira.

No Instagram, rede social de vídeos e imagens, na qual o Brasil se destaca com o quarto maior público do mundo, já navegam ao menos 35 iniciativas criativas sobre oceano, em português, sendo a grande maioria liderada por mulheres biólogas. A maior presença feminina na rede e nas páginas que divulgam ciência é uma tendência também no Canadá [7]. Estudo de Jarreau e colegas [8] que analisaram o uso do Instagram por museus de história natural conclui que a comunicação acaba sendo mais institucional e as instituições perdem a oportunidade de sensibilizar o público para o trabalho de pesquisa realizado e para a divulgação da ciência enquanto processo, não apenas os seus resultados. Ao mesmo tempo, os autores identificaram pouco uso de pessoas e "selfies" nas postagens, o que impulsionaria não apenas o engajamento social, mas também a imagem mais humanizada da ciência - pontos que precisamos ter em mente se quisermos embarcar nas redes sociais e interagir com o público.

UMA CAMBADA DE ARTIGOS A pesquisa científica internacional sobre oceano tem apresentado aumento significativo. Uma busca pela produção científica mundial usando a palavra-chave "ocean" nos campos de título e resumo do artigo no Dimensions, um dos indexadores de maior cobertura de revistas científicas do mundo, revela um total de 2,8 milhōes de artigos, sendo que 128 mil estão em acesso aberto, e pouco mais de 17 mil artigos foram publicados apenas em 2020. A maior parte deles sobre ciências da Terra e oceanografia e 258 relativos ao Brasil. 


\section{Dicas de podcasts que tratam do tema "oceano"}

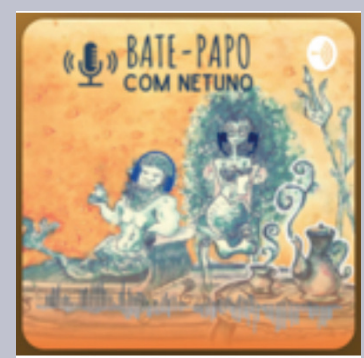

Bate-Papo com Netuno

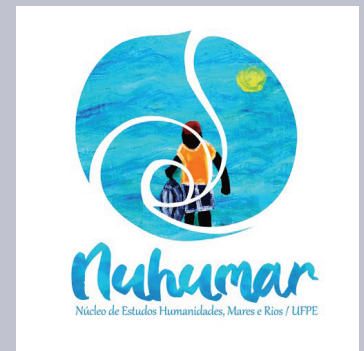

Vozes da Pesca Artesanal

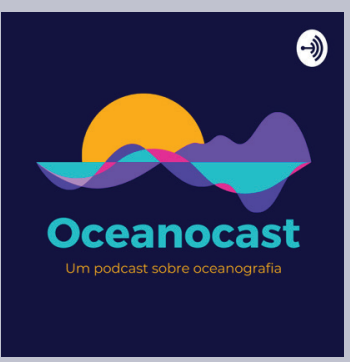

Ocean Cast

\section{$\oplus$

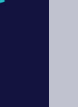

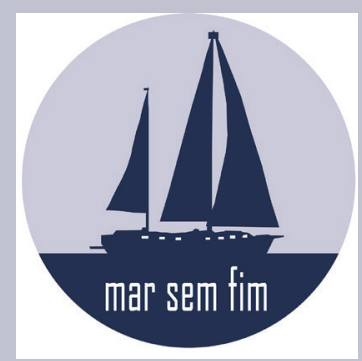

Mar Sem Fim

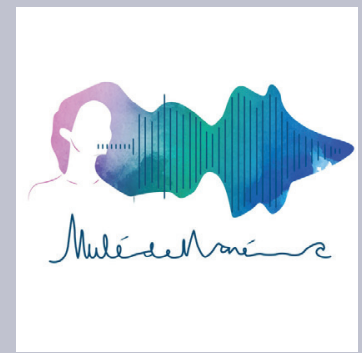

Mulé de Maré 